\title{
The Effect of Geometric Parameters on the Performance of Solar Chimney: A Numerical and Experimental Study
}

\author{
Abdelkader Lahcene \\ Laboratory of Materials and Reactive Systems \\ Djillali Liabes University of Sidi Bel Abbes \\ Sidi Bel Abbes, Algeria \\ lhkader@yahoo.fr
}

\author{
Abdel Yllah Benazza \\ Laboratory of Materials and Reactive Systems \\ Djillali Liabes University of Sidi Bel Abbes \\ Sidi Bel Abbes, Algeria \\ abdel_benazza@yahoo.fr
}

\author{
Mohamed Benguediab \\ Laboratory of Materials and Reactive Systems \\ Djillali Liabes University of Sidi Bel Abbes \\ Sidi Bel Abbes, Algeria \\ benguediab_m@yahoo.fr
}

\begin{abstract}
A numerical and experimental study of the geometric parameters of the solar chimney on the aerodynamic and thermal behavior of the air flow is presented in this paper. Several configurations were proposed in order to optimize the most efficient geometric one. Mass conservation, continuity, and energy equations are solved by the finite volume method. The increase in the radius of the collector and the inclination angle of the roof of the collector contributes favorably to the flow velocity to reach its maximum below the level of the tower, whereas it is inversely proportional to the height of the collector (space: ground-roof). This hangs up the height and the opening of the chimney generates a significant relaxation between the glue and the exit, from where important velocity is recorded at the level of the glue. A good correlation between the experimental and the simulation results is observed.
\end{abstract}

Keywords-solar chimney; natural convection; collector; finish volume; opening angle;inclination

\section{INTRODUCTION}

Exploitation and consumption of fossil fuels have a considerable impact on the environment, emitting carbon dioxide $\left(\mathrm{CO}_{2}\right)$, a greenhouse gas largely responsible for climate change, whereas the overexploitation of their reserves will lead to their depletion. These causes have led the research to develop and exploit renewable energy sources. Among these alternative energy sources, solar energy is virtually inexhaustible. Several studies on solar energy exploitation have been carried out, such as the study and simulation of solar flux on the walls of buildings in Adrar (Algeria) [1] and the effect of hydronic solar heaters for the Algerian climate [2]. The solar tower or solar chimney is a solar energy generating installation that uses solar radiation to increase the internal energy of the air entering a system. The solar energy received by the air through the collector will be transformed into kinetic energy and then into electricity by a suitable turbine. The solar tower is suitable for countries with strong solar radiation or sunshine. It has three main parts, namely the collector, the chimney, and the turbine. The adaptability of solar energy for a given application depends on the performance of the solar chimney. Understanding the fundamental mechanisms governing the operation of the chimney allows the mastery of all the extrinsic or intrinsic parameters entering into the energy transfer process in order to optimize its performance.

Solar chimneys have been studied by many researchers. Leonardo da Vinci made sketches of a solar tower called a smoke outlet [3]. The idea of using a solar chimney for the production of electricity was first developed in 1903 [4]. This concept was taken up by Günther [5] in 1931 who gave a detailed description and the authors in [6] developed and implemented this project. The first prototype was made in 1982 in Manzanares, Spain. From there a series of theoretical studies continued, which developed theoretical models of solar chimneys by deriving the yield and Mullett performance data [7]. Several theoretical and experimental studies relating to the determination of the profile of the velocity and the temperature inside the chimney as a function of height, angle of inclination, temperature of the ambient air, and intensity of solar radiation were carried out. Authors in [8] modeled the heat transfer and the air flow in the CCS with the hypothesis of a laminar flow in natural convection. Authors in $[9,10]$ studied numerically the natural laminar convection and permanent air in a solar chimney. Authors in [11] aimed at the development of an analytical and numerical model making possible to describe the performance of solar chimneys. Authors in [12] developed a numerical model to simulate the performance of a stack solar power plant in different regions of Iran. Authors in [13] made a thermal development of the laminar flow with hydrodynamic

Corresponding author: Mohamed Benguediab 
development of a viscoplastic fluid (Bingham fluid) between two plane plates. This analysis showed the effect of the inertia and the rheological behavior of the fluid on the velocity fields, pressure and temperature. Authors in [14] developed a mathematical model which described the flow rate and the performance evaluation of the solar chimney with different functional and geometric configurations. The effect of the slope on the flow out of the stack was studied by authors in [15], which showed that the absorption is optimal, for an angle of inclination varying between $40^{\circ}$ and $60^{\circ}$. The processes of heat transfer and efficiency of natural ventilation driven by a solar chimney have been studied in [16]. Authors in [17] published a review of the main characteristics of chimney solar power plants. Authors in [4-6] carried out several studies on the optimization of various parameters such the height of the chimney and the angle of inclination of the collector.

In the present study, a combination of the variation of three geometric parameters (chimney height, inclination angle of the collector and inclination angle of the chimney) is made in order to obtain the optimal values of the performance of the solar chimney. This work aims to optimize the geometric parameters of the chimney in order to obtain an efficient configuration. Several configurations are studied numerically and experimentally.

\section{SimUlATION}

\section{A. Geometry}

The creation of the chimney geometry is based on three two-dimensional elements (surfaces) on the (x,y) plane. The collector is a horizontal rectangle with a length (radius $\mathrm{R}_{\text {coll }}$ ) of $12 \mathrm{~m}$ and a width (height $\mathrm{h}_{\text {coll }}$ ) of $0.8 \mathrm{~m}$, the collector has a junction with the chimney by a converging elbow of radius $0.8 \mathrm{~m}$. The chimney is a vertical rectangle with a length (height $\mathrm{H}_{\mathrm{ch}}$ ) of $12 \mathrm{~m}$ and a width of $0.8 \mathrm{~m}$. Figure 1 represents the geometric parameters of the studied chimney. The adopted mathematical model is established using the following simplifying assumptions: the flow is two-dimensional and the system admits an axis of symmetry, the flow is turbulent, the considered fluid is assumed to be viscous and Newtonian, and obeys Boussinesq's approximation. The properties of the fluid are assumed to be constant and with no heat source.

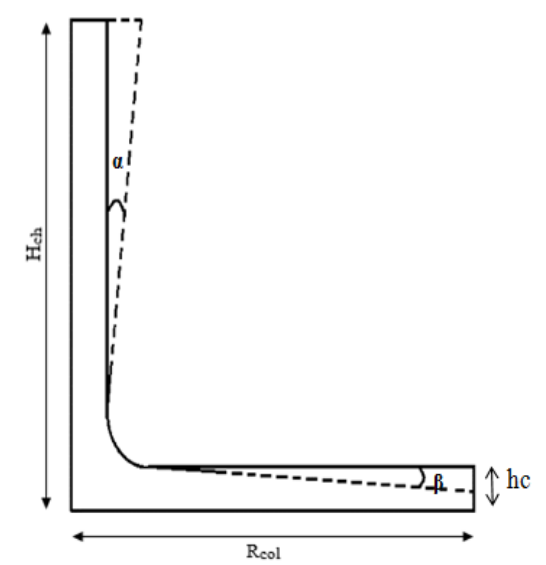

Fig. 1. Geometry of the studied solar chimney.

\section{B. Numerical Procedure}

The numerical calculation is based on the finite volume discretization of the transport equations on a 2-D structured mesh. The variables are stored in a non-shifted mesh (collocated) via the interpolation of Rhie [18]. The pressure correction is performed using the Simple algorithm. The generation of the mesh is an adapted 2-D mesh that is structured, monoblock and curvilinear of the bodyfitted type. Mesh dependence was investigated using different numbers of mesh before attaching to a $32 \times 376$ mesh (Figure 2 ).

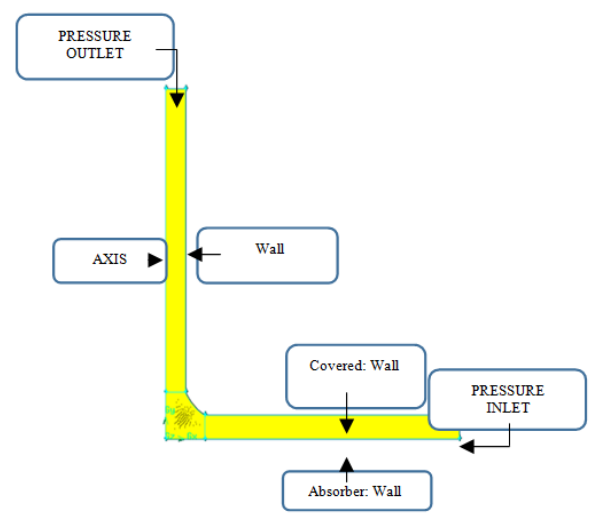

Fig. 2. Boundary conditions.

\section{EXPERIMENTAL PART}

In this part, a prototype of a solar fireplace inspired by prototypes from France and Iran was designed (Figure 3). The effect of the geometric parameters of the solar chimney on the temperature and the air flow velocity were studied. The measurements were carried out during May, where the atmospheric disturbances are caused by the wind and the passage of clouds, during a period going from 10:20 a.m. to 3:05 p.m. Readings were taken every 15 minutes. Three geometrical configurations have been tested. The different configurations are given in Table I.

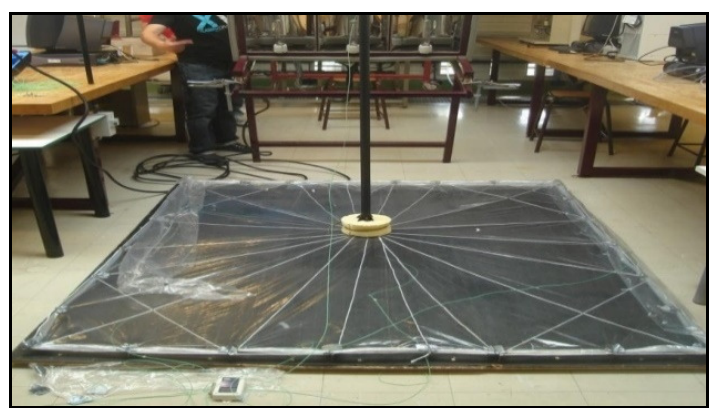

Fig. 3. The experimental prototype, made in our laboratory.

TABLE I. GEOMETRICAL CONFIGURATIONS

\begin{tabular}{|c|c|c|}
\hline \multirow{2}{*}{ Configuration } & \multicolumn{2}{|c|}{ Dimensions of the prototype } \\
\cline { 2 - 3 } & Chimney height $\mathbf{( m m )}$ & $\begin{array}{c}\text { Inclination } \alpha=\mathbf{1 2 . 7}^{\circ} \\
\text { for collector height } \mathbf{( m m})\end{array}$ \\
\hline 1 & 665 & 155 \\
\hline 2 & 1835 & 155 \\
\hline 3 & 1835 & 120 \\
\hline
\end{tabular}




\section{RESULTS AND DISCUSSION}

\section{A. Numerical Results}

The influence of the opening angle of the tower, the angle of inclination of the collector, the height of the tower, the height of the collector and the radius of the collector on the flow rate and the maximum flow velocity have been studied.

\section{1) Influence of the Opening Angle of the Chimney}

Figures 4 and 5 represent the iso-velocity for different values of the opening angle $\alpha$ for a collector radius of $15 \mathrm{~m}$ and $20 \mathrm{~m}$. It should be noted that the velocity intensity and the position of its focus vary according to the angle $\alpha$. The velocity in the chimney increases as the radius of the collector and the opening angle increase.

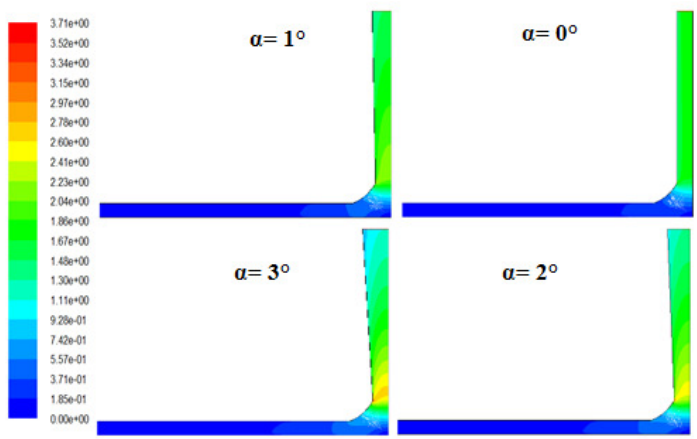

Fig. 4. Iso-velocity contours for different opening angles $\alpha$ and for a collector radius of $15 \mathrm{~m}$.

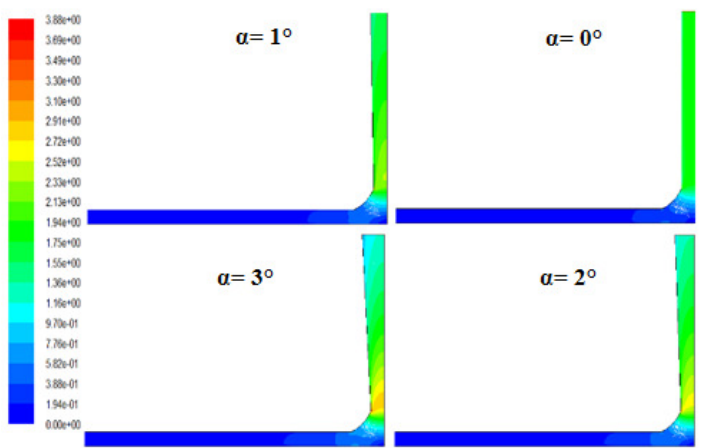

Fig. 5. Iso-velocity contours for different opening angles $\alpha$ and for a collector radius of $20 \mathrm{~m}$.

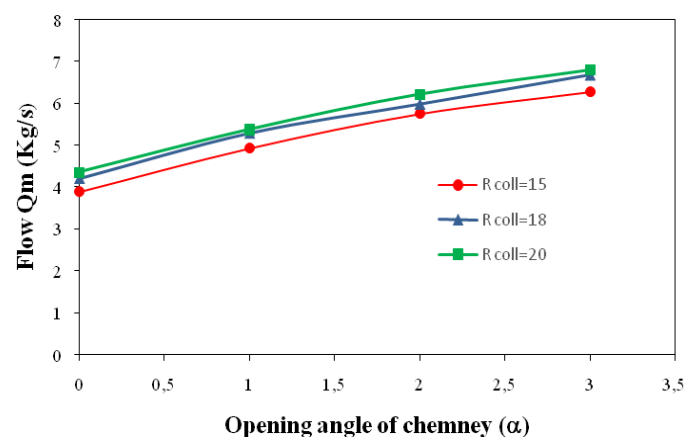

Fig. 6. Flow variation as a function of the opening angle of chimney $\alpha$ for different collector radius values.
The quantitative aspect of these results is illustrated by Figures 6 and 7 where a significant increase in the maximum velocity and the flow can be noticed. This can be explained by the increase in the heat exchange surface (large collector radius) and as a result the increase in air temperature, therefore significant buoyancy.

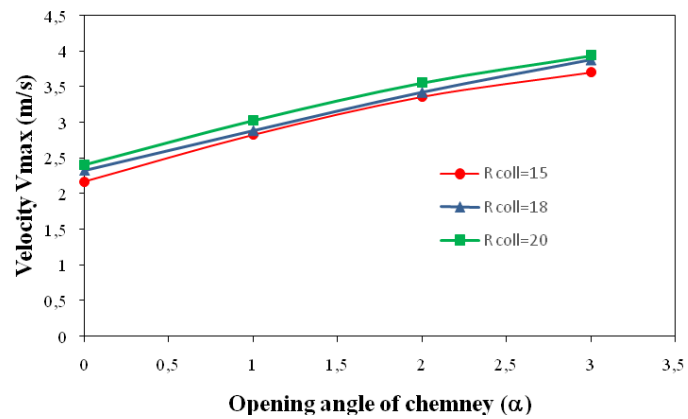

Fig. 7. Velocity variation as a function of the opening angle of chimney $\alpha$ for different collector radius values.

\section{2) Influence of the Collector Inclination Angle}

Figures 8 and 9 represent the iso-velocity for different angle openings for collector inclination angle $\beta=0$ and $\beta=3^{\circ}$.

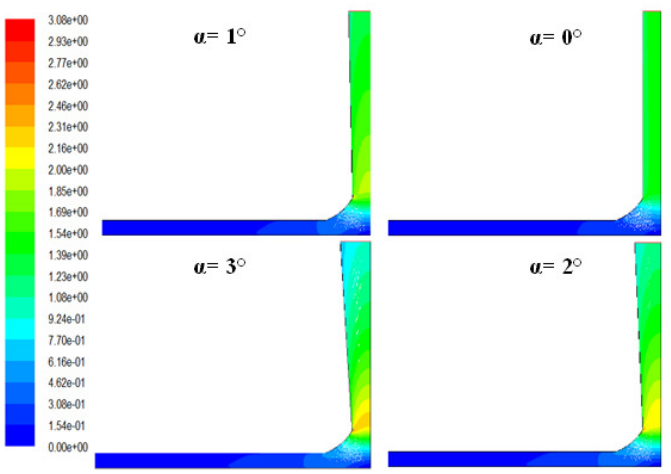

Fig. 8. Iso-velocity contours for different opening angles $\alpha$ and collector inclination angle $\beta=0$.

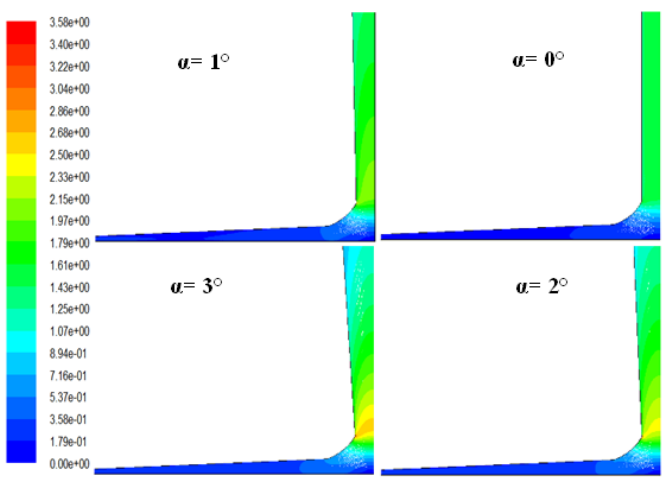

Fig. 9. Iso-velocity contours for different opening angles $\alpha$ and collector inclination angle $\beta=3^{\circ}$.

It is noted that as the angle of inclination $\beta$ of the collector roof increases, the velocity through the system increases to a 
maximum at the foot of the tower. Increasing the angle $\beta$ decreases the phenomenon of recirculation of the flow at the inlet of the collector. The opening of the chimney generates significant relaxation between the neck and the outlet, where the high velocity is recorded at the neck. These results are quantitatively illustrated by Figures 10 and 11 showing respectively the variations of the flow rate and the maximum velocity as functions of the opening angle.

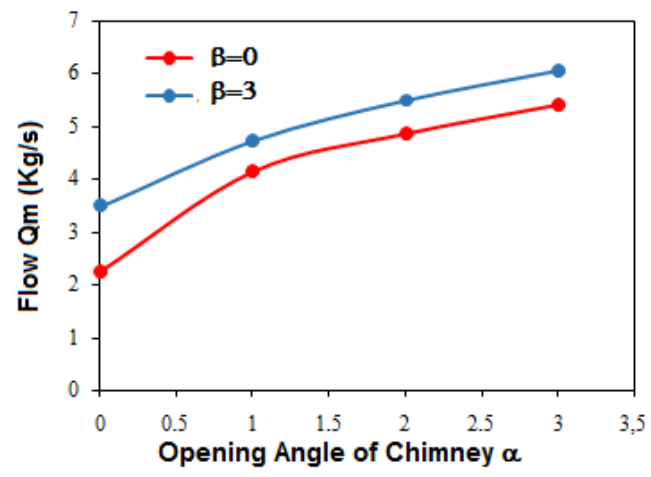

Fig. 10. Comparison between the variation of flow as a function of $\alpha$ for $\beta=0^{\circ}$.

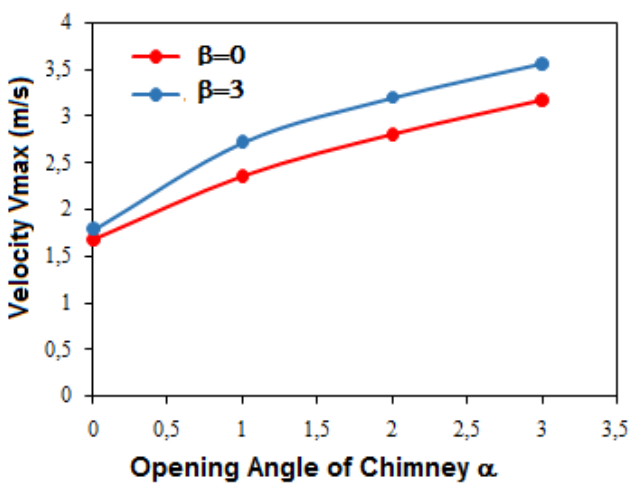

Fig. 11. Comparison between the variation of velocity as a function of $\alpha$ for $\beta=0^{\circ}$.

\section{B. Experimental Results}

Three different configurations were tried in order to study the temperature and velocity variations (see Table II). An Arduino system was used, which consists of placing digital temperature and velocity sensors in different parts of the chimney, as shown in Figure 12.

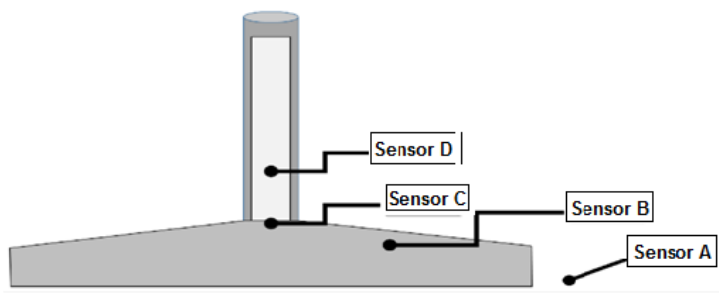

Fig. 12. Aeras of temperature and velocity readings.
TABLE II. STUDIED GEOMETRIC PARAMETERS

\begin{tabular}{|c|c|c|c|}
\hline \multirow{2}{*}{ Configuration } & \multicolumn{3}{|c|}{ Dimensions of the prototype } \\
\cline { 2 - 4 } & $\begin{array}{c}\text { Chimney } \\
\text { height }(\mathbf{m m})\end{array}$ & $\begin{array}{c}\text { Collector height } \\
\text { (mm) }\end{array}$ & Inclination \\
\hline 1 & 665 & 155 & 12.7 \\
\hline 2 & 1835 & 155 & 12.7 \\
\hline 3 & 1835 & 120 & 14.47 \\
\hline
\end{tabular}

\section{1) Temperature Variation as a Function of Time}

Figures 13-15 give the temperature variation as a function of time in different areas of the solar chimney. Temperatures are measured at points A, B, C, for the three chimney configurations defined in Table II.

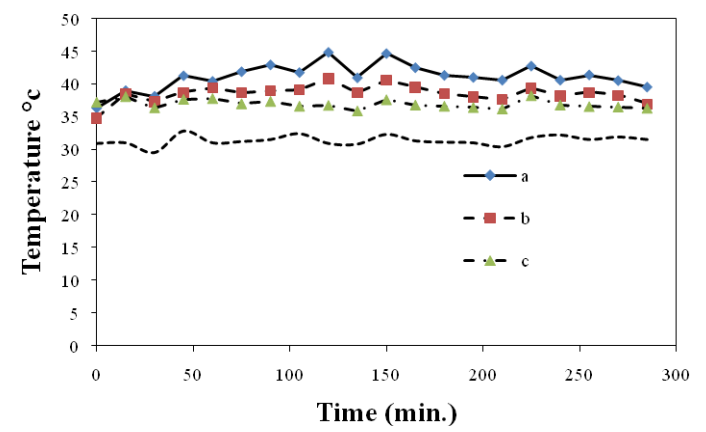

Fig. 13. Variation of temperature as a function of time in areas A, B, C for configuration 1 .

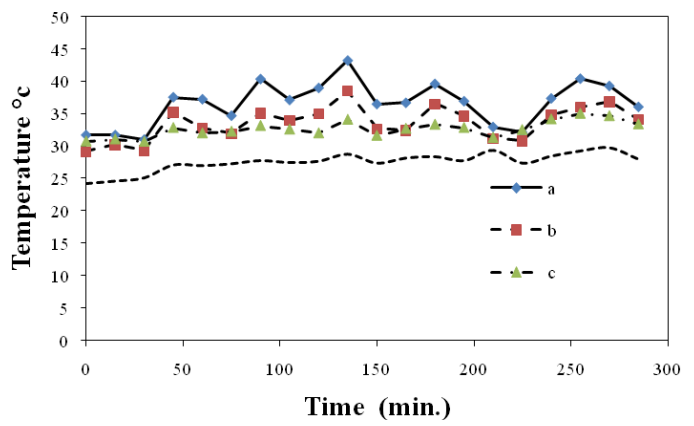

Fig. 14. Variation of temperature as a function of time in areas A, B, C for configuration 2 .

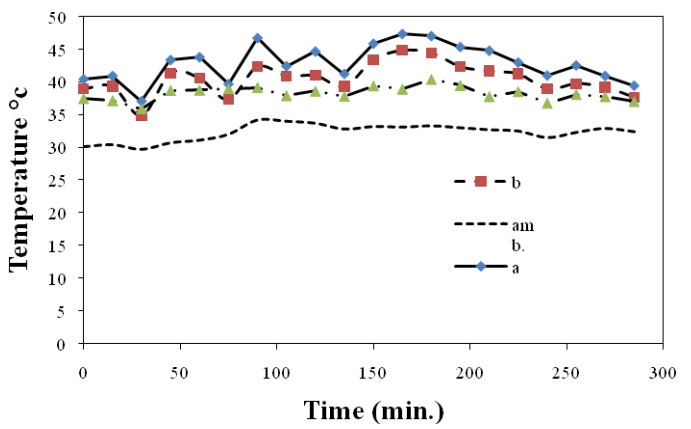

Fig. 15. Variation of temperature as a function of time in areas A, B, C for configuration 3 .

A gradual increase is noticed in the temperature in the collector (inlet-outlet), due to the greenhouse effect below the collector roof. A slight difference between the temperature at 
point $\mathrm{B}$ and at point $\mathrm{C}$ was also noticed. This difference can be explained by heat losses due to the vortex and the poor insulation at the neck. The temperature in the chimney recorded at point $\mathrm{D}$ is lower than that recorded at point $\mathrm{C}$. This decrease is the consequence of the transformation of thermal energy into kinetic energy (thermosiphon phenomenon).

\section{2) Velocity Variation as a Function of Time}

The effect of the geometric parameters on the variation of velocity in the chimney was studied in two zones of the chimney: $\mathrm{BC}$ and $\mathrm{DC}$. The variation of the velocity in these zones for configurations 1-3 is given in Figures 16-18.

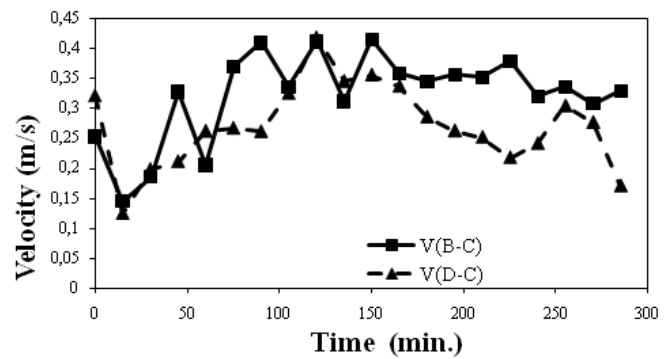

Fig. 16. Variation of velocity as a function of time in zones BC and DC for configuration 1 .

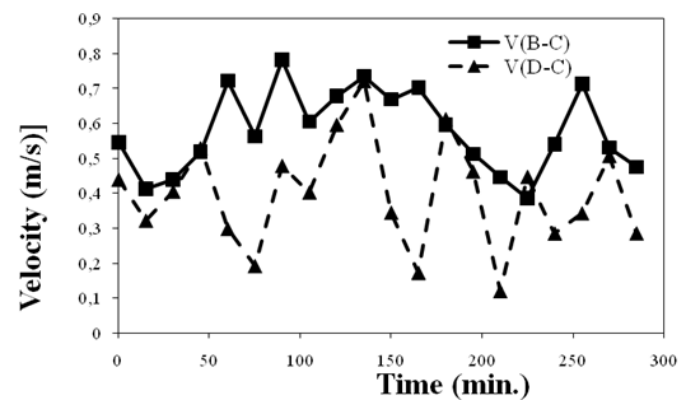

Fig. 17. Variation of velocity as a function of time in zones BC and DC for configuration 2 .

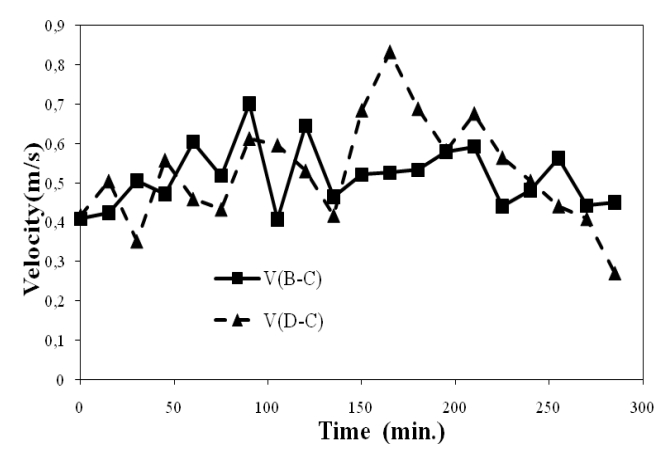

Fig. 18. Variation of velocity as a function of time in zones BC and DC for configuration 3 .

We can see that this variation differs from case to case and from area to area. For the first configuration, there is not a large difference between the maximum and minimum velocity values in the two zones (Figure 16). The values recorded in the DC zone are $0.4171 \mathrm{~m} / \mathrm{s}$ for maximum velocity and $0.1245 \mathrm{~m} / \mathrm{s}$ for minimum velocity. In the $\mathrm{BC}$ zone the recorded values are
$0.4108 \mathrm{~m} / \mathrm{s}$ and $0.1447 \mathrm{~m} / \mathrm{s}$ respectively. For the second configuration, there is a notable difference in the values recorded in the two zones (Figure 17).The maximum and minimum values recorded in the DC zone are $0.7206 \mathrm{~m} / \mathrm{s}$ and $0.1191 \mathrm{~m} / \mathrm{s}$. On the other hand, the maximum and minimum values in the $\mathrm{BC}$ zone are $0.7832 \mathrm{~m} / \mathrm{s}$ and $0.3863 \mathrm{~m} / \mathrm{s}$. Note that despite the fact that the ambient temperature of the configuration is lower than that prevailing in the first configuration, the flow velocity values are two times those of the first configuration. There is a positive effect on the performance due to the height of the chimney. This evolution can be explained by the fact that when the height increases, the thermosiphon phenomenon becomes more important. The effect of the inclination of the collector is studied in the third configuration, with the same chimney height and by modifying the height of the inlet of the collector (Figure 18). It is noted that the velocity gradient is greater than the one recorded in the second configuration. The inclination of the manifold positively contributes to the variation of velocity in the chimney. In this configuration, the maximum and minimum values recorded were $0.8321 \mathrm{~m} / \mathrm{s}$ and $0.2704 \mathrm{~m} / \mathrm{s}$ for the $\mathrm{DC}$ zone. On the other hand, in the $\mathrm{BC}$ zone, the values were $0.7013 \mathrm{~m} / \mathrm{s}$ and $0.4063 \mathrm{~m} / \mathrm{s}$ respectively.

\section{Conclusion}

The main aim of this study was to investigate the effect of the geometric parameters of the solar chimney on the aerodynamic and thermal behavior of the air flow. The work was split into two parts:

The first part was a numerical simulation of the air flow in the chimney under the effect of variation of the opening radius of the chimney and the inclination of the manifold. It has been shown that these two parameters have an important influence on the flow rate and therefore on the efficiency of the solar chimney.

In the second part, a prototype was made. The effects of the height of the chimney and the tilt of the header on the velocity and temperature of the air in the chimney were studied. The obtained results allowed us to validate the numerical results and predict the most suitable area for the location of the turbine.

\section{ACKNOWLEDGMENT}

This work was carried out in the Laboratory of Materials and Reactive Systems of Djillali Liabes University of Sidi Bel Abbes which is sponsored by the direction of scientific and technological research (DGRST Algeria).

\section{REFERENCES}

[1] A. Oudrane, B. Aour, B. Zeghmati, X. Chesneau, and H. Massaoud, "Study and Simulation of the Density of the Incident Solar Flux on the Walls of a Building in Adrar, Algeria," Engineering, Technology \& Applied Science Research, vol. 7, no. 5, pp. 1940-1945, Oct. 2017, https://doi.org/10.48084/etasr.1337.

[2] I. Zeghib and A. Chaker, "Efficiency of a Solar Hydronic Space Heating System under the Algerian Climate," Engineering, Technology \& Applied Science Research, vol. 6, no. 6, pp. 1274-1279, Dec. 2016, https://doi.org/10.48084/etasr.875. 
[3] R. Wengenmayr and T. Bührke, Eds., Renewable Energy: Sustainable Energy Concepts for the Future, 1st ed. Weinheim, Germany: Wiley$\mathrm{VCH}, 2008$.

[4] I. Cabanyes, "Las chimeneas solares (Solar chimneys)," La ernergia eléctrica, 1903.

[5] H. Günther, In hundert Jahren - Die künftige Energieversorgung der Welt, 1 st ed. Kosmos, 1931.

[6] J. Schlaich et al., "The solar chimney-Transferability of results from the Manzanares solar chimney plant to larger scale-plants," Schlaich Bergermann und Partner CEs, Stuttgart, Germany, 1995.

[7] L. B. Mullett, "The solar chimney-overall efficiency, design and performance," International Journal of Ambient Energy, vol. 8, no. 1, pp. 35-40, Jan. 1987, https://doi.org/10.1080/01430750.1987.9675512.

[8] T. Chergui, S. Larbi, and A. Bouhdjar, "Thermo-hydrodynamic aspect analysis of flows in solar chimney power plants-A case study," Renewable and Sustainable Energy Reviews, vol. 14, no. 5, pp. 1410 1418, Jun. 2010, https://doi.org/10.1016/j.rser.2010.01.017.

[9] T. Tayebi and D. Mahfoud, "Numerical Simulation of Natural Convection in a Solar Chimney," International Journal of Renewable Energy Research, vol. 2, no. 4, pp. 712-717, Dec. 2012.

[10] T. Tayebi and M. Djezzar, "Numerical Analysis of Flows in a Solar Chimney Power Plant with a Curved Junction," International Journal of Energy Science, vol. 3, no. 4, pp. 280-286, Aug. 2013.

[11] M. A. dos S. Bernardes, A. Voß, and G. Weinrebe, "Thermal and technical analyses of solar chimneys," Solar Energy, vol. 75, no. 6, pp. 511-524, Dec. 2003, https://doi.org/10.1016/j.solener.2003.09.012.

[12] A. Asnaghi and S. M. Ladjevardi, "Solar chimney power plant performance in Iran," Renewable and Sustainable Energy Reviews, vol. 16, no. 5, pp. 3383-3390, Jun. 2012, https://doi.org/10.1016/ j.rser.2012.02.017.

[13] A. Boualit, N. Zeraibi, S. Boualit, and M. Amoura, "Thermal development of the laminar flow of a Bingham fluid between two plane plates with viscous dissipation," International Journal of Thermal Sciences, vol. 50, no. 1, pp. 36-43, Jan. 2011, https://doi.org/ 10.1016/j.ijthermalsci.2010.09.005.

[14] A. Kasaeian, M. Ghalamchi, and M. Ghalamchi, "Simulation and optimization of geometric parameters of a solar chimney in Tehran," Energy Conversion and Management, vol. 83, pp. 28-34, Jul. 2014, https://doi.org/10.1016/j.enconman.2014.03.042.

[15] J. Mathur, N. K. Bansal, S. Mathur, M. Jain, and Anupma, "Experimental investigations on solar chimney for room ventilation," Solar Energy, vol. 80, no. 8, pp. 927-935, Aug. 2006, https://doi.org/10.1016/j.solener.2005.08.008.

[16] A. Li, P. Jones, P. Zhao, and L. Wang, "Heat Transfer and Natural Ventilation Airflow Rates from Single-sided Heated Solar Chimney for Buildings," Journal of Asian Architecture and Building Engineering, vol. 3, no. 2, pp. 233-238, Nov. 2004, https://doi.org/10. 3130/jaabe.3.233.

[17] X. Zhou, F. Wang, and R. M. Ochieng, "A review of solar chimney power technology," Renewable and Sustainable Energy Reviews, vol. 14, no. 8, pp. 2315-2338, Oct. 2010, https://doi.org/10.1016/ j.rser.2010.04.018.

[18] C. M. Rhie and W. L. Chow, "Numerical study of the turbulent flow past an airfoil with trailing edge separation," AIAA Journal, vol. 21, no. 11, pp. 1525-1532, Nov. 1983, https://doi.org/10.2514/3.8284. 